\title{
Effects of Growth Factors on Development of Fetal Islet B-Cells In Vitro
}

\author{
Masahiko YASUDA $^{1)}$, Masako YAMAMOTO ${ }^{1)}$, Hideharu OCHIAI'), Yasunobu EGUCHI') and Kazuyoshi ARISHIMA ${ }^{1)}$ \\ ${ }^{1)}$ Department of Anatomy II, ${ }^{2)}$ Research Institute of Bioscience, School of Veterinary Medicine, Azabu University, Sagamihara, Kanagawa \\ 229-8501, Japan
}

(Received 24 November 2006/Accepted 25 April 2007)

\begin{abstract}
To investigate the role of growth factors (epidermal growth factor [EGF], betacellulin, and activin A) in the development of islet B cells of rat fetal pancreatic explants in vitro, pancreases from rat fetuses at day 18 of gestation were cultured for $96 \mathrm{hr}$, with or without these growth factors. Culture medium was changed every $24 \mathrm{hr}$, and the level of insulin released in the culture medium was measured. After $72 \mathrm{hr}$ of culture, pancreases were examined histologically. As a result, EGF promoted cell proliferation, but reduced $\mathrm{B}$ cell volume. Whereas, betacellulin and activin A inhibited cell division, but promoted increased B cell volume and insulin secretion, especially activin A, which stimulated insulin release in a time dependent manner. These results suggest that EGF, betacellulin, and activin A promote pancreatic cell proliferation, islet B-cell differentiation, and islet B-cell differentiation and functional maturation, respectively, and that EGF, betacellulin, and activin $\mathrm{A}$, in this order, regulate islet $\mathrm{B}$-cell neogenesis.
\end{abstract}

KEY WORDS: B cell, growth factors, in vitro, pancreatic islets, rat.

J. Vet. Med. Sci. 69(8): 807-811, 2007

In rat fetuses, the insulin-producing B-cells first appear as early as on day 12 of gestation [28], followed by the rapidly increase in its cell population size on day 16 of gestation [13]. There was a continuous increase in the population size, with the fastest increase occurring in the last 4 days of gestation. The accelerated growth of these islet cell populations during late gestation was accomplished by a high cell proliferative activity at 19-21 days of gestation [12]. Porhta et al. [16], who injected STZ (an experimental diabetogenic agent) directly into the vitelline vein of the fetus on day 19 of gestation, showed a fall in the pancreatic and plasma insulin levels. This fall in insulin levels recovered after 3 days. On day 19 of gestation, the direct administration of STZ to rat fetuses immediately decreases the total mass of islet B cells, but these cells are markedly restored after $48 \mathrm{hr}$ [23]. In vitro, we previously reported that after damage by STZ to islet B cells on day 18 gestation, the total mass of islet B-cells and the insulin secretory function were improved [24, 27].

From an experiment using adult NOD mice, a mouse model of type 1 diabates, neogenesis/regeneration of islet Bcells seemed to occur via the redifferentiation of surviving islet cells [5] and neogenesis primarily with differentiation from epithelial cells of secretory ducts [10]. In rat fetal pancreas treated with STZ both in vivo and in vitro [24, 27], the progenitor cells of islet B-cells seem to exist in epithelial cells of secretory ducts.

In the developmental process, extracellular signal proteins cause a variety of cell types to proliferate and differentiate. Epidermal growth factor (EGF) is a polypeptide originally extracted from the submaxillary glands of mice [2]. It is reported that EGF has a growth-stimulatory effect

\footnotetext{
* Correspondence to: Yamamoto, M., Department of Anatomy II, School of Veterinary Medicine, Azabu University, Sagamihara, Kanagawa 229-8501, Japan.

e-mail: masako@azabu-u.ac.jp
}

on isolated rat islets [1]. Betacellulin (BTC), a member of the EGF family, has been extracted from mouse insulinom cell lines [19]. It is reported that BTC transforms pancreatic acinar cells derived from adult rat pancreas tumors into pancreatic endocrine cells [14]. Activin A (Act.A), a member of the transforming growth factor- $\beta$ superfamily, regulates the differentiation and maturation of pancreatic islet cells [25]. It is reported that activin A has an insulin-secretion promoting effect on isolated rat islets $[7,22,26]$. However, these reports were performed using separated pancreatic exocrine tissue or isolated pancreatic islets. No reports have used organ culture of the whole pancreas.

Our previous study showed that the addition of EGF to cultured medium does not trigger the regeneration of islet $\mathrm{B}$ cells in STZ-treated pancreas [27]. It is important to elucidate the effects of growth factors on normal development in fetal pancreases, prior to examining the role of growth factors in the recovery of B cells in STZ-treated pancreases. Therefore, we planned this study to examine how growth factors (EGF, BTC, and Act.A) are involved to regulate the development of intact fetal pancreatic islet, especially B cells, in vitro.

\section{MATERIALS AND METHODS}

Jcl:Wistar rats (CLEA, Tokyo, Japan) were used. The rats were given a commercial diet (Labo MR Breeder, Nihon Nosan Kogyo, Japan) and water, both ad libitum. Females were placed with males overnight and were examined the next morning for the presence of sperm in vaginal smears. The day on which sperm was detected was counted as day 0 of gestation. The study described in this article was carried out in accordance with the Azabu University Animal Experimental Guidelines.

Pancreases were cultured from 18-day fetuses. Fetuses were removed from maternal uteri under aseptic conditions 
and transferred to sterile petri dishes containing Hanks' balanced salt solution (HBSS; Sigma-Aldrich, Inc., MO, U.S.A.) with $0.35 \mathrm{mg} / \mathrm{mL} \mathrm{NaHCO}_{3}$, penicillin (100 units/ $\mathrm{mL})$, and streptomycin $(100 \mu \mathrm{g} / \mathrm{mL})$. The fetal pancreases were removed and rinsed with HBSS. Each pancreas was placed on the surface of a Millipore filter on top of a stainless-steel grid in a culture dish (NUNC A/C, Roskilde, Denmark) containing medium (Medium RPMI 1640; GibcoBRL, N.Y., U.S.A.), including $20 \mathrm{mM}$ HEPES, $16.7 \mathrm{mM}$ $\mathrm{D}(+)$-glucose, $5 \mathrm{mg} / \mathrm{mL}$ bovine albumin (Sigma-Aldrich), 2 $\mathrm{mg} / \mathrm{mL}$ sodium bicarbonate, penicillin (100 units $/ \mathrm{mL}$ ), and streptomycin $(100 \mu \mathrm{g} / \mathrm{mL})$. All cultures were incubated at $37^{\circ} \mathrm{C}$ in a humidified atmosphere of $5 \% \mathrm{CO}_{2}$ in air. All of the above procedures were performed under sterile conditions.

For $6 \mathrm{hr}$, pancreases were cultured and then divided into 4 groups: the first group was cultured with normal medium, as the Control group; the second group was cultured with $100 \mathrm{ng} / \mathrm{mL}$ EGF (Sigma-Aldrich), as group EGF; the third group was cultured with $1.0 \mathrm{mg} / \mathrm{mL}$ betacellulin (BTC, Genzyme Techne, MN, U.S.A.), as group BTC; the fourth group was cultured with $2.0 \mathrm{mg} / \mathrm{mL}$ activin A (Act.A., Genzyme Techne), as group Act. A. The EGF concentration in the culture medium was prepared as previously reported [27], and the concentrations of BTC and Act. A. were decided in accordance with our preliminary experiments(BTC:0.1, 1.0, 10, and $100 \mathrm{mg} / \mathrm{mL}$; Act.A: 2.0 and 50 $\mathrm{mg} / \mathrm{mL})$. After pre-incubation, the pancreases were cultured for $96 \mathrm{hr}$, changing the medium every $24 \mathrm{hr}$. The exchanged media were stored at $-80^{\circ} \mathrm{C}$ until being assayed. The concentration of insulin in the medium was measured by radioimmunoassay using a rat insulin $\left[{ }^{125} \mathrm{I}\right]$ assay system (GE Healthcare Bio-Sciences Corp., NJ, U.S.A.).

After $72 \mathrm{hr}$ of culture, explants were fixed in $10 \%$ buffered formalin, dehydrated in a graded series of ethanol, embedded in Paraplast (McCormick Scientific LLC., MO,U.S.A.), and sectioned serially at $4 \mu \mathrm{m}$. The sections were double-immunostained for insulin and proliferating cell nuclear antigen (PCNA). In brief, the sections were firstly immunostained with mouse polyclonal anti-PCNA serum (diluted 1:1,000; PC10, Santa Cruz Biotechnology, Inc., CF, U.S.A.) by the avidin-biotin-peroxidase complex (ABC) method and developed with 3,3'-diaminobenzidine tetrahydrochloride (DAB)- $\mathrm{NiCl}_{2}$. The same tissue sections were then immunostained with rabbit polyclonal anti-insulin antibody (diluted 1:1,000; DiaSorin, Inc., MN, U.S.A.) by the ABC method and developed with DAB. The sections were counterstained with hematoxylin. To estimate the cell division index, the number of PCNA-positive cells per 2,000 cells within all pancreatic cells, namely islet cells, epithelial cells of secretory ducts, and acinar cells, was determined. To estimate the volumes of insulin cells and the total explant mass, the area of every fifth section of a series of insulin-positive cells and the area of sectional explants were measured with an image analyzing apparatus (Image Command 5098; Olympus Industry Co., Tokyo, Japan). The total volume of the insulin-positive cells and volume of whole cultured pancreas were calculated as follows: the total volume of insulin-positive cells (A) $\left(\mu \mathrm{m}^{3}\right)=$ sum of areas of insulin-positive cells $\left(\mu \mathrm{m}^{2}\right) \times 20 \mu \mathrm{m}$ (distance between the sections); the volume of whole explants (B) $\left(\mu \mathrm{m}^{3}\right)=$ sum of areas of the sectional explants $\left(\mu \mathrm{m}^{2}\right) \times 20$ $\mu \mathrm{m}$, the ratio of insulin-positive cells in a cultured pancreas $=\mathrm{A} / \mathrm{B}$. Fifty insulin-positive cells from each explant were measured to quantify the sectional area.

All parametric data are shown as the mean \pm S.E.M. Statistical analyses were made with Duncan's new multiple range test. A p value less than 0.05 was considered significant.

\section{RESULTS}

Immunohistochemical observation: In the pancreas at 18 days of gestation used in this experiment, the majority of pancreatic islet cells were B-cells, and some PCNA-positive cells were observed in epithelial cells of secretory ducts (Fig. 1A). When pancreases were cultured in medium with EGF (EGF group), many ducts were observed compared with those in the Control group, and many PCNA-positive cells were observed in the epithelial cells of secretory ducts (Fig. 1B). In the BTC group, most secretory ducts showed small numbers of PCNA-positive nuclei, but a few pancreatic islet cells also exhibited PCNA reactivity. In the Act.A group, it seemed that the number of pancreatic ductal epithelial cells with a PCNA-positive nucleus decreased, while in the mesenchymal tissue, many cells had a PCNA-positive nucleus.

The ratio of insulin-positive cells in the pancreas explants: In the EGF group, the ratio of the volume of insulin-positive cells to the total volume of the pancreas explant (A/B ratio) significantly decreased compared with that of the Control group (Fig. 2). In the BTC group, the A/B ratio was significantly larger than that of the Control group. In the Act. A group, the A/B ratio was significantly larger than that of the Control group, but the average sectional area of insulin-positive cells was significantly smaller (Figs. 2 and 3).

Cell division index: The addition of EGF to the culture medium significantly increased the cell division index of PCNA-positive pancreatic cells, but the addition of BTC or Act.A significantly decreased the cell division index; furthermore, Act.A more strongly suppressed cell division than BTC (Fig. 4).

Level of insulin released: In the Control group, the level of insulin released into the culture medium increased significantly, starting from $48 \mathrm{hr}$ of culture in a time-dependent manner (Fig. 5). In the EGF group, the level of insulin secretion significantly increased until $48 \mathrm{hr}$ of culture, but thereafter decreased in comparison with the Control group. After $24 \mathrm{hr}$ of culture, the levels of insulin released were almost equal. In the BTC group, the level of insulin secretion significantly increased until $72 \mathrm{hr}$ of culture in comparison with the Control group, and the levels of insulin released were almost equal to the EGF group. In the Act.A 


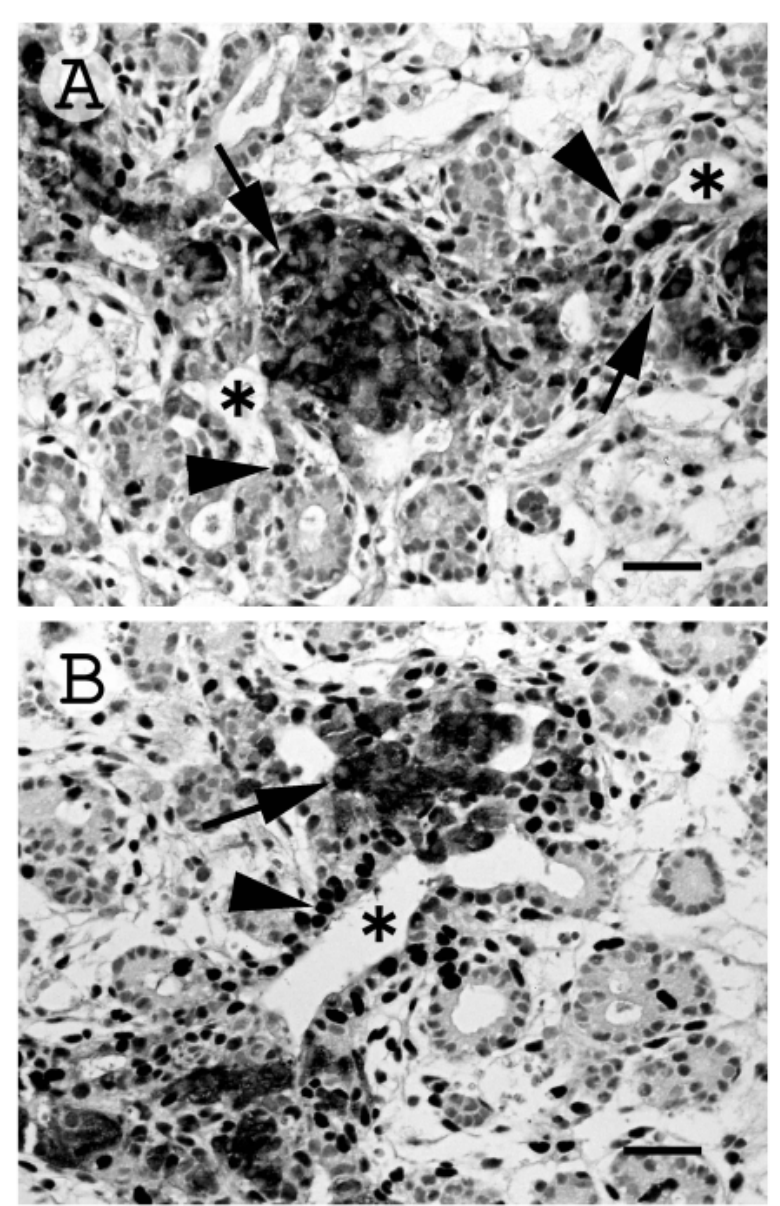

Fig. 1. Double immunostaining with anti-insulin and anti-PCNA serum. Sections of cultured fetal pancreas of the Control (A) and EGF (B) groups. Clusters of pancreatic islet B-cells (arrows) are in contact with secretory ducts (asterisks). PCNA-positive cells (arrowheads) are observed in secretory ducts. In all groups, the structures of pancreatic acini and secretory ducts are well maintained. Scale bars, $25 \mu \mathrm{m}$.

group, the level of insulin secretion markedly increased after $24 \mathrm{hr}$ of culture in comparison with the Control group, and the levels of insulin secretion increased markedly in a time-dependent manner, unlike the EGF and BTC groups.

\section{DISCUSSION}

It is generally accepted that all endocrine cells of pancreatic islets arise from ductal epithelial stem cells through sequential differentiaton $[11,17,21]$. Moreover, it was suggested that the precursor cells of pancreatic islet B-cells regarded as newly appearing were in pancreatic duct cells. The histological observations in this study and our previous results $[24,27]$ showed that the origin of B-cells newly formed during development was secretory duct cells. A recent study has reported that the origin of the turnover of adult mouse islet B-cells is not from stem cells, but from the self-replication of pre-existing islet B cells [3]. However,

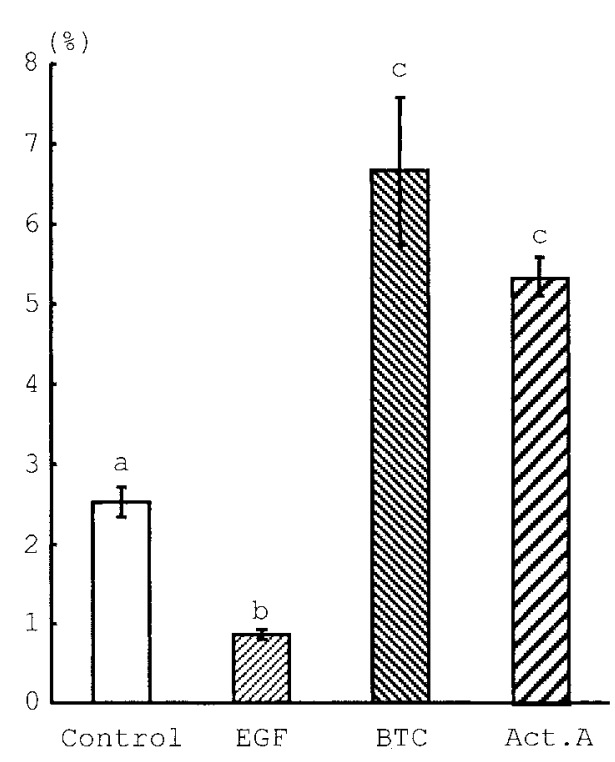

Fig. 2. The ratio of insulin-positive cells in cultured fetal pancreases in each group at $72 \mathrm{hr}$ after treatment. Each value is expressed as the mean \pm SEM based on 6 determinations. a, b, and $\mathrm{c}$ indicate significant differences from the other groups $(\mathrm{P}<0.05)$

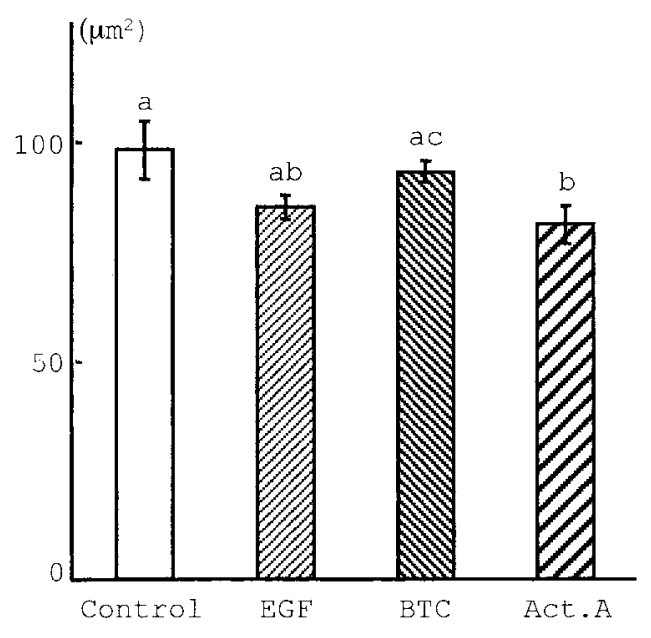

Fig. 3. The average cross-sectional area of insulinpositive cells in cultured fetal pancreases at $72 \mathrm{hr}$ after treatment for each group. Each value is expressed as the mean \pm SEM based on 6 determinations. a, b, and $\mathrm{c}$ indicate significant differences between groups $(\mathrm{P}<0.05)$.

this is an event involved in the turnover of adult pancreatic islet B-cells, and does not seem to apply to the fetal islets in this study.

Addition of EGF increased the level of insulin released from the fetal pancreas at $24 \mathrm{hr}$ of culture, but thereafter did not promote insulin release. On the other hand, EGF addition increased the cell division index by $50 \%$ at $72 \mathrm{hr}$ of culture. This finding suggests that EGF promotes the 


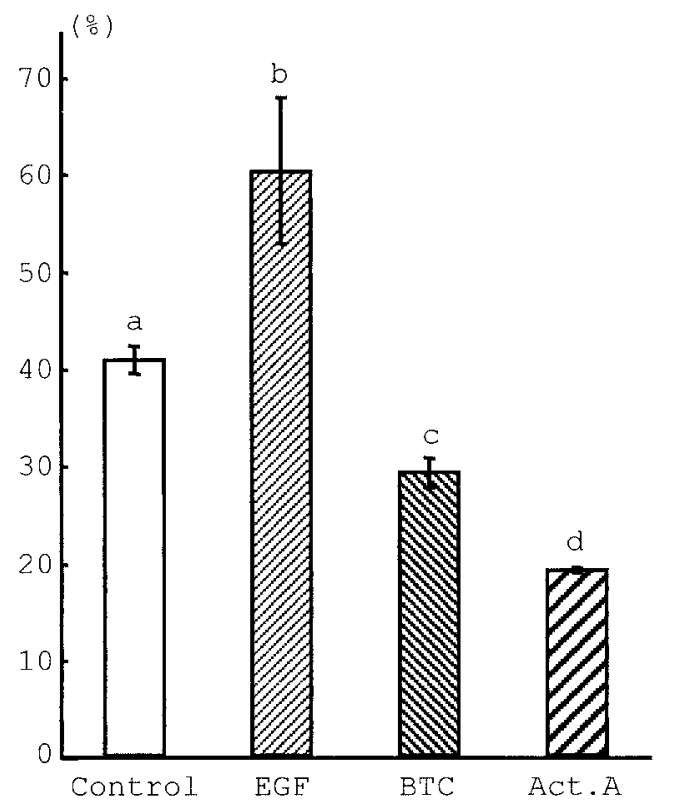

Fig. 4. The ratio of PCNA-positive cells (the cell division index) in cultured fetal pancreases at $72 \mathrm{hr}$ after treatment for each group. Each value is expressed as the mean \pm SEM based on 6 determinations. $a, b$, and $c$ indicate significant differences between groups $(\mathrm{P}<0.05)$.

proliferation of fetal islet cells under culture conditions. However, the addition of EGF reduced the A/B ratio and the sectional area of B cells at $72 \mathrm{hr}$ of culture, suggesting that during the culture period, EGF promotes cell division to increase immature B-cells, but inhibits the functional differentiation or maturation of $\mathrm{B}$-cells to reduce the $\mathrm{A} / \mathrm{B}$ ratio. This speculation is also supported by the lack of an increase in insulin release in the EGF group after $24 \mathrm{hr}$ of culture. Although there have been no reports on the effect of EGF on the fetal pancreas, EGF has been reported to promote the division of isolated rat islet cells [1]. Also, it has been reported that when adult rat islets are cultured in EGF-supplemented medium for $72 \mathrm{hr}$, the uptake of ${ }^{3} \mathrm{H}$-leucine for proinsulin synthesis increases [1], and the insulin content of islets tends to increase [20]. Therefore, it appears that EGF promotes the functional maturation of adult rat islet B-cells, but conversely inhibits the differentiation of B-cells in the fetal pancreas.

It has been reported that betacellulin converts rat pancreatic exocrine AR42J cells into endocrine cells, which express mRNA for glucokinase and enzymes involved in the synthesis of GLUT2 and insulin, and stimulation by potassium promotes insulin secretion [14], leading to the concept that betacellulin induces differentiation (transformation) of pancreatic exocrine cells into insulin-secreting cells. In this study, betacellulin markedly reduced cell division, but nevertheless increased the B-cell volume and the level of insulin released, indicating that betacellulin inhibits the proliferation of new B-cells, but promotes the differentia-

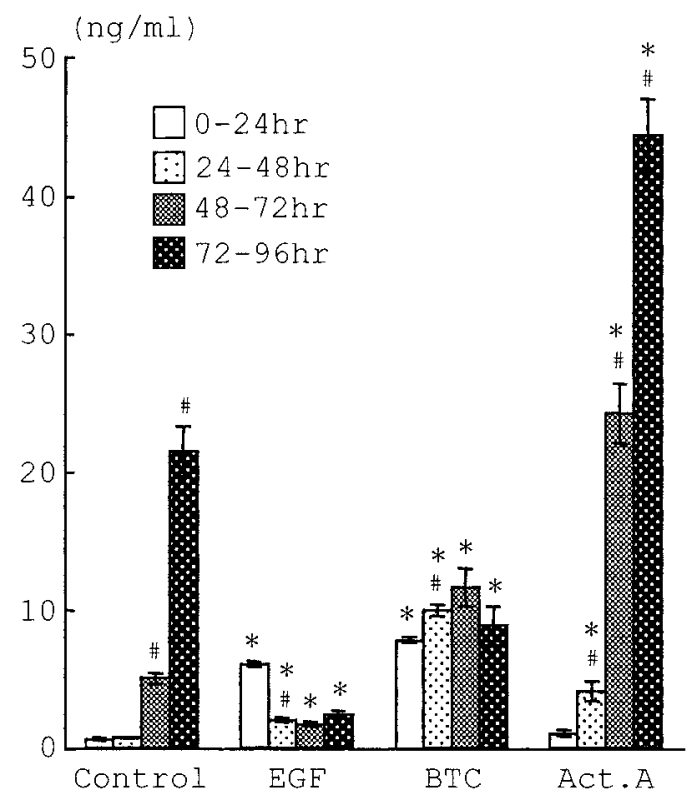

Fig. 5. Changes in the level of insulin released into the culture medium. Each value is expressed as the mean \pm SEM based on 6 determinations. * indicates a significant difference from the Control group at the same period. " indicates a significant difference from the preceding period in the same group $(\mathrm{P}<0.05)$.

tion and functional maturation of undifferentiated B-cells.

Addition of activin A strongly promoted the release of insulin from the cultured pancreas from $24 \mathrm{hr}$ of culture. No experimental studies using organ-cultured pancreases have reported the in vitro action of activin A on pancreatic Bcells, although those using isolated rat islets have. It has been reported that activin A promotes the secretion of insulin from isolated rat islets [22], and this is the result of activin A promoting the influx of $\mathrm{Ca}^{2+}$ into pancreatic islet B-cells [18]. These observations suggest that, also in the pancreas cultured in this study, activin A promoted the influx of $\mathrm{Ca}^{2+}$ into normal pancreatic islet $\mathrm{B}$ cells, thereby promoting insulin secretion. In addition, activin A reduced the cell division index of the pancreas, but increased the total volume of islet B-cells, suggesting that similar to betacellulin, activin A inhibits the neosynthesis of islet cells and promotes the functional and morphological differentiation of pancreatic islet B-cells. Activin A has been reported to be present in adult rat islet A and D cells [26], and to be expressed in undifferentiated cells of the pancreatic anlage of 12-day-old rat embryos [6]. Moreover, the theory that undifferentiated cells expressing activin A differentiate into islet cells has been advanced $[4,6]$. For many years, the relationship between the differentiation of the pancreatic anlage and the surrounding mesenchymal tissue has been investigated, and it is well known that in the presence or absence of mesenchymal tissue in vitro, exocrine and endocrine cells, respectively, differentiate from the pancreatic anlage [8]. It has been reported that in mesenchymal tissue around the rat 
pancreatic anlage, follistatin is present and antagonizes activin $\mathrm{A}$ in undifferentiated cells [15]. This suggests that activin $\mathrm{A}$ is involved in the differentiation of islet cells. In this study, activin A did not promote the neogenesis of islet B-cells, but is presumably involved in the functional maturation of islet cells, particularly islet B-cells.

Signal transducer and activator of transcript 3 (STAT3) is an EGF-reactive mediator downstream of growth factors such as betacellulin, hepatocyte growth factor, growth hormone, and heparin-binding EGF-like factor. In STAT3 knockout mice, islet B-cells have no ability to differentiate, and the morphology of islets is not maintained [9]. These observations suggest that the growth factors used in this study are essential for islets to develop in fetal life. In addition, the results of this study suggest that EGF, betacellulin, and activin A promote pancreatic cell proliferation, islet Bcell differentiation, and islet B-cell differentiation and functional maturation, respectively, and that the interaction of these factors regulates islet B-cell neogenesis.

\section{REFERENCES}

1. Chatterjee, A. K., Sieradzki, J. and Schatz, H. 1986. Epidermal growth factor stimulates (pro-) insulin biosynthesis and ${ }^{3} \mathrm{H}$-thymidine incorporation in isolated pancreatic rat islets. Horm. Metabol. Res. 18: 873-874.

2. Cohen, S. 1962. Isolation of a mouse submaxillary gland protein accelerating incisor eruption and eyelid opening in newborn animal. J. Biol. Chem. 237: 1556-1562.

3. Dor, Y., Brown, J., Martinez, O. I. and Melton, D. A. 2004. Adult pancreatic $\beta$-cells are formed by self-duplication rather than stem-cell differentiation. Nature 429: 41-46.

4. Demeterco, C., Beattie, G. M., Dib, S. A., Lopez, A. D. and Hayek, A. 2000. A role for activin A and betacellulin in human fetal pancreatic cell differentiation and growth. J. Clin. Endocrinol. Metab. 85: 3892-3897.

5. Fernandes, A., King, L. C., Guz, Y., Stein, R., Wright, C. V. E. and Teitelman, G. 1997. Differentiation of new insulin-producing cells is induced by injury in adult pancreatic islets. Endocrinology 138: 1750-1762.

6. Furukawa, M., Eto, Y. and Kojima, I. 1995. Expression of immunoreactive activin A in fetal rat pancreas. Endocr. J. 42: 63-68.

7. Furukawa, M., NobU.S.A.wa, R., Shibata, H., Eto, Y. and Kojima, I. 1995. Initiation of insulin secretion in glucose-free medium by activin A. Mol. Cell. Endocrinol. 113: 83-87.

8. Gittes, G. K., Galante, P. E., Hanahan, D., Rutter, W. J. and Debase, H. T. 1996. Lineage-specific morphogenesis in the developing pancreas: role of mesenchymal factors. Development 122: 439-447.

9. Gorogawa, S., Fujitani, Y., Kaneto, H., Hazama, Y., Watada, H., Miyamoto, Y., Takeda, K., Akira, S., Magnuson, M. A., Yamasaki, Y., Kajimoto, Y. and Hori, M. 2004. Insulin secretory defects and impaired islet architecture in pancreatic $\beta$-cellspecific STAT3 knockout mice. Biochem. Biophys. Res. Commun. 319: 1159-1170.

10. Gu, D., Lee, M.-S., Krahl, T. and Sarvetnick, N. 1994. Transitional cells in the regenerating pancreas. Development $\mathbf{1 2 0}$ : 1873-1881

11. Hellerström, C. and Swenne, I. 1991. Functional maturation and proliferation of fetal pancreatic $\beta$-cells. Diabetes $\mathbf{4 0}$
(Suppl.) 2: 89-93.

12. Kaung, H-L.C. 1994. Growth dynamics of pancreatic islet cell populations during fetal and neonatal development of the rat. Dev. Dyn. 200: 163-175.

13. Komatsu, S., Yamamoto, M., Takizawa, T., Shirai, M., Arishima, K. and Eguchi, Y. 1996. Effect of maternal adrenalectomy and corticosterone therapy on the early development of B-cells in the fetal islet in the rat. J. Vet. Med. Sci. 58: 995-999.

14. Mashima, H., Ohnishi, H., Wakabayashi, K., Mine, T., Miyagawa, J., HanafU.S.A., T., Seno, M., Yamada, H. and Kojima, I. 1996. Betacellulin and activin A coordinately convert amylase-secreting pancreatic AR42J cells into insulin-secreting cells. J. Clin. Invest. 97: 1647-1654.

15. Miralles, F., Czernichow, P. and Scharfmann, R. 1998. Follistatin regulates the relative proportions of endocrine versus exocrine tissue during pancreatic development. Development 125: 1017-1024.

16. Porhta, B., Levacher, C., Picon, L. and Rosselin, G. 1974. Diabetogenic effect of streptozotocin in the rat during the perinatal period. Diabetes 23:889-895.

17. Rosenberg, L. and Vinik, A. I. 1992. Trophic stimulation of the ductual-islet cell axis: a new approach to the treatment of diabetes. Adv. Exp. Med. Biol. 321: 95-104.

18. Shibata, H., Yasuda, H., Sekine, N., Mine, T., Totsuka, Y. and Kojima, I. 1993. Activin A increases intracellular free calcium concentrations in rat pancreatic islets. FEBS Lett. 329: 194198.

19. Shing, Y., Christofori, G., Hanahan, D., Ono, Y., Sasada, R., Igarashi, K. and Folkman, J. 1993. Betacellulin: A mitogen from pancreatic $\beta$-cell tumors. Science 259: 1604-1607.

20. Sjöholm, ̊̊, Welsh, N., Sandler, S. and Hellerström, C. 1990. Role of polyamines in mitogenic and secretory responses of pancreatic $\beta$-cells to growth factors. Am. J. Physiol. 259: C828C833.

21. Swenne, I. 1992. Pancreatic $\beta$-cell growth and diabetes mellitus. Diabetologia 35: 193-201.

22. Totsuka, Y., Tabuchi, M., Kojima, I., Shibai, H. and Ogata, E. 1988. A novel action of activin A: stimulation of insulin secreting in rat pancreatic islet. Biochem. Biophys. Res. Commun. 156: 335-339.

23. Yamamoto, M., Kudoh, A., Arishima, K. and Eguchi, Y. 1997. Immunocytochemical changes in the fetal pancreatic islet following fetal administration of streptozotocin in the rat. Anat. Rec. 247: 248-252.

24. Yamamoto, M., Yasuda, M., Hori, A., Arishima, K. and Eguchi, Y. 2004. Recovery in the fetal pancreatic islet following fetal administration of streptozotocin in the rat in vivo and in vitro. Anat. Rec. 281A: 1319-1325.

25. Yamaoka, T., Idehara, C., Yano, M., Matsushita, T., Yamada, T., Ii, S., Moritani, M., Hata, J., Sugino, H., Noji, S. and Itakura, M. 1998. Hypoplasia of pancreatic islets in transgenic mice expressing activin receptor mutants. J. Clin. Invest. 102: 294-301.

26. Yasuda, H., Inoue, K., Shibata, H., Takeuchi, T., Eto, Y., Hasegawa, Y., Sekine, N., Totsuka, Y., Mine, T., Ogata, E. and Kojima, I. 1993. Existence of activin A in A- and D- cells of rat pancreatic islet. Endocrinology 133: 624-630.

27. Yasuda, M., Yamamoto, M., Arishima, K. and Eguchi, Y. 2002. Effects of epidermal growth factor (EGF) on fetal islet B cells in vitro. J. Vet. Med. Sci. 64: 101-105.

28. Yoshinari, M. and Daikoku, S. 1982. Ontogenic appearance of immunoreactive endocrine cells in rat pancreatic islets. Anat. Embryol. 165: 63-70. 